\title{
The Inspiration of Subaru as a Symbol of Cultural Values and Traditions in Japan
}

\begin{abstract}
Steven L. Renshaw
Abstract. Subaru is known by many throughout the world as the Japanese name for the Pleiades. Having some basis as a seasonal marker in antiquity and later appearance in the development of national mythology, imagery related to Subaru developed to reflect cultural values, and its seasonal appearance served as a practical guide for numerous activities of the culture. To gain a basic understanding of how symbolic associations with Subaru have been inspired by its place in the heavens as well as its use for citizens, four areas of interest are viewed: (1) astronomical and seasonal significance of the asterism as reflected in early Asian cosmology, (2) associations in the national mythology of the sun goddess Amaterasu, (3) lore found throughout the islands related to practical uses of Subaru as a marker for time keeping, agriculture, fishing, and other activities, and (4) individual and cultural symbolism associated with archetypal identification
\end{abstract}

\section{Introduction}

Apart from identification with a car company, Subaru is known by many throughout the world as the Japanese name for the Pleiades, an asterism that has played a major role in the life and history of many cultures. ${ }^{1}$ Having some basis as a seasonal marker in antiquity and later development in national mythology, imagery related to Subaru developed to reflect cultural values, and its seasonal appearance served as a practical guide for numerous activities of the culture. It is difficult to specify an exact English equivalence for the name Subaru, but it may generally be translated by terms such as 'united', 'gathered', 'getting together', 'grouping', or 'congregated', referring to the appearance of the asterism. Nojiri has argued that authoritative opinion about the origin of the name Subaru was established by Edo era (1603-1867) scholars of the classics. ${ }^{2}$

\footnotetext{
${ }^{1}$ E.C. Krupp, Beyond the Blue Horizon: Myths and Legends of the Sun, Moon, Stars, and Planets (New York: Oxford University Press, 1991), pp. 241-55.

${ }^{2}$ H. Nojiri, Seimei Jiten (Dictionary of Star Names in Japan) (Tokyo: Tokyo Do Shuppan, 1973); H. Nojiri, Seiza Meguri (Tour of the Constellations) (Tokyo:

Steven L. Renshaw, 'The Inspiration of Subaru as a Symbol of Cultural Values and Traditions in Japan', eds. Nicholas Campion and Rolf Sinclair, Culture and Cosmos, Vol. 16 nos. 1 and 2, 2012, pp. 175-191.

www.CultureAndCosmos.org
} 
176 The Inspiration of Subaru as a Symbol of Cultural Values and Traditions in Japan

It was generally thought to consist of seven stars and describe the shape of a congregated object. ${ }^{3}$

To gain a basic understanding of how symbolic associations with Subaru have been inspired by its place in the heavens as well as its use in the daily life of citizens, four areas of interest are viewed: (1) astronomical and seasonal significance of the asterism as reflected in early Asian cosmology, (2) associations in the national mythology of the sun goddess Amaterasu, (3) lore found throughout the islands related to practical uses of Subaru as a marker for time-keeping, agriculture, fishing, and other activities, and (4) individual and cultural symbolism associated with archetypal identification.

\section{Astronomical and Seasonal Significance}

There is no indigenous written record of what early inhabitants of the Japanese islands observed in the sky, and any assertion of what was known by the Japanese prior to the Common Era is at best speculative. However, precessional calculation, comparison with what is known about other Asian cultures, and archaeological evidence can provide an idea of what was probably understood about celestial phenomena and how they were used, an understanding of the seasonal significance of Subaru in later centuries of the Common Era. Sun and Kistemaker indicate that the Pleiades must have been a 'landmark' on the calendar of pastoral nomads throughout Asia by the second or third centuries and was probably known by most inhabitants even two to three thousand years earlier. ${ }^{4}$ Building on their premise, around $2400 \mathrm{BCE}$, the spring equinox was quite near this asterism. A full moon near Subaru would have indicated an opposite sun

Seibundou Shinkousha, 1987); and H. Nojiri, Hoshi no Shinwa Densetsu Shusei (Collection of Mythology and Star Legends) (Tokyo: Koseisha Koseikaku, 1988).

${ }^{3}$ There are many variants and diverse local and regional meanings. In this paper, variations in italics are noted by different spellings. Some terms may have similar Chinese characters but different pronunciation, not only in Chinese to Japanese transformations but in local dialects as well. Japanese etymological references in I. Shinmura ed., Koujien (Japanese Etymological Dictionary) (Tokyo: Iwanami Shoten, 1994); U. Ozaki et al., eds., Dai Ji Gen (Great Origins of Words) (Tokyo: Kadokawa Shoten, 1993) should be consulted for more indepth explanation.

4 X. Sun, and J. Kistemaker The Chinese Sky During the Han: Constellating Stars and Society (New York: Brill, 1997), p. 16. 
quite near the autumn equinox. In this era, Subaru, near the zenith after sunset in winter (around 6:00 or 7:00 pm), would have indicated the sun being near winter solstice, a point significant for predicting the return of spring. Figure 1 may be used to visualize this configuration.

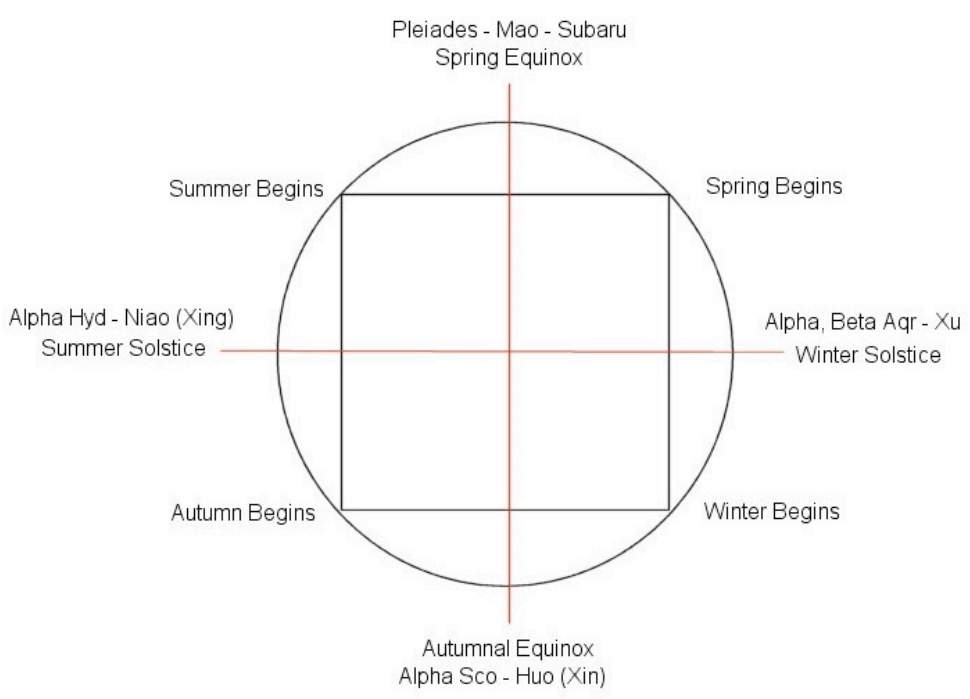

Figure 1. Solstices, Equinoxes, and Sectional Terms in about 2400 BCE relative to Four Cardinal Asterisms as noted in the Canon of Yao in the Book of Documents. ${ }^{5}$

In the subsequent two to three thousand years, the position of the vernal equinox shifted from Subaru, and the early centuries CE found the asterism between the positions of the vernal equinox and summer solstice, much closer to the sectional term Rikka (Summer Begins, about 6 May). ${ }^{6}$ In this era, viewing Subaru on the zenith just after sunset in

5 Based on Sun and Kistemaker, Chinese Sky, pp. 15-21; J. S. Major, Heaven and Earth in Early Han Thought: Chapters Three, Four, and Five of the Huainanzi (New York: State University of New York Press, 1993), pp. 32-43.

${ }^{6}$ For further description of terms and methods used in the history of the Japanese calendar, consult Y. Okada and S. Akune, Gendai Koyomi Yomikaki Jiten (Modern Calendar Dictionary) (Tokyo: Kashiwa Shoubou, 1993); for discussion in Japanese and the less detailed English account of Japanese calendars in A. Campbell and D. S. Noble, Japan: An Illustrated Encyclopedia. (Tokyo: Kodansha, 1993), pp. 154-55. 
178 The Inspiration of Subaru as a Symbol of Cultural Values and Traditions in Japan

winter would indicate that the season lay between the winter solstice and the vernal equinox, closer to the sectional term Risshun (Spring Begins, about 4 February (See Figure 2). As indicated by Sun and Kistemaker, even with changes due to precession, the asterism maintained seasonal significance, especially in relation to the coming of spring.

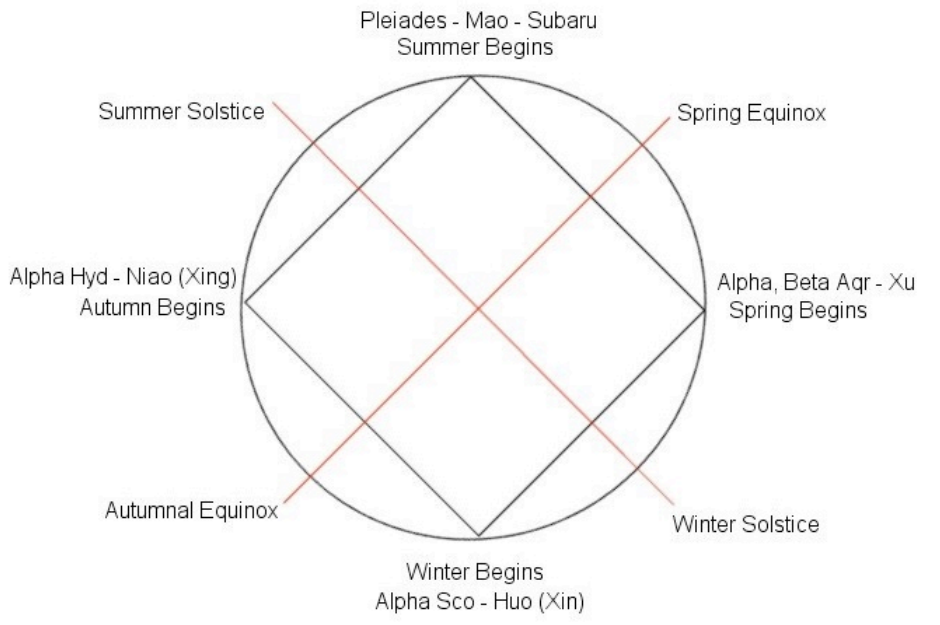

Figure 2. Solstices, Equinoxes, and Sectional Terms in about $600 \mathrm{CE}$ relative to the Four Cardinal Asterisms as noted in the Canon of Yao in the Book of Documents.

The nomadic behaviour of the Japanese in the Jomon Period - the huntergatherer society from about $12,000 \mathrm{BCE}$ to $400 \mathrm{BCE}$ - is well documented, and many archaeologists argue that a knowledge of celestial movement was necessary for predicting times of movement as well as availability of food supplies. ${ }^{8}$ Mizoguchi asserts that sites such as the rather well-known stone circles of northern Japan which have been dated to the latter Jomon period (from about 2400 BCE) were probably

\footnotetext{
${ }^{7}$ Based on Sun and Kistemaker, Chinese Sky, pp. 15-21; J. S. Major, Heaven and Earth, pp. 32-43.

${ }^{8}$ K. Imamura, Prehistoric Japan: New Perspectives on Insular East Asia (London: University College London Press, 1996); C.M. Aiken and T. Higuchi, Prehistory of Japan (New York: Academic Press, 1982).
} 
constructed 'in accordance with the movement of heavenly bodies' and 'were designed to map out the rhythm of the cycle of the year and to enable those who experienced the place by either living there or participating in formalized practices conducted there to engage in the life cycle'. Many of these sites consist of crude configurations of stones, including gnomon-like structures that could be used to determine solar movement. ${ }^{10}$ These were not observatories devoted to the study of astronomy but rather an integral part of the living space of those who inhabited them on a seasonal basis.

Noting the linguistic association of Subaru with the jewels of the sun goddess Amaterasu discussed in the next section, ritual objects found at these sites are of particular interest. These include many feminine figurines as well as large numbers of jewel beads (magatama in Japanese). Mizoguchi sees these sites with their associated ritualistic objects as a fundamental part of the Jomon, a period he describes as a 'pool of non-historical cyclical/repetitive matters'. ${ }^{11}$ Though the exact nature of original ritualistic activity is not known, forms and oral traditions of activities were carried into the Yayoi period (the agrarian society from about $400 \mathrm{BCE}$ to $375 / 400 \mathrm{CE}$ and the Kofun period (named after the tomb mounds constructed at the time, from around 250 to before $600 \mathrm{CE}$ and were incorporated into legends such as the aforementioned seasonally-based myth of Amaterasu. ${ }^{12}$

To place it in a historical context, the Yayoi period brought many imports and migration from the Asian continent. Japan, a primarily nomadic hunter-gatherer society, turned into one more devoted to agriculture, primarily the production of rice. Infusions of Buddhism with its sanctity of the 'north seven stars' (Big Dipper or Hokutoshichisei in Japanese) as well as formal astronomical knowledge (including calendar reckoning) increased in the seventh century $\mathrm{CE} \cdot{ }^{13} \mathrm{~A}$ formal position for

\footnotetext{
${ }^{9}$ K. Mizoguchi, An Archaeological History of Japan: 30,000 BC to AD 700 (Philadelphia: University of Pennsylvania Press, 2002), p. 106.

${ }^{10}$ For full descriptions of these sites and their seasonal associations, the reader should consult sources mentioned in the text and in R.J. Pearson, G. L. Barnes and K.L. Hutterer, eds., Windows on the Japanese Past: Studies in Archaeology and Prehistory (Ann Arbor, University of Michigan: Center for Japanese Studies, 1986).

${ }^{11}$ Mizoguchi, Archaeological Japan, p. 34.

${ }^{12}$ Mizoguchi, Archaeological Japan, pp. 25-38.

${ }^{13}$ S. Nakayama, A History of Japanese Astronomy: Chinese Background and Western Impact (Cambridge: Harvard University Press, 1969); M. Sugimoto and
} 
180 The Inspiration of Subaru as a Symbol of Cultural Values and Traditions in Japan

Subaru was found among the imported system of moon stations or mansions (sei shuku in Japanese). Each of the four celestial animals in Chinese cosmology (azure dragon of spring, black warrior or tortoise of winter, white tiger of autumn, and vermillion bird of summer) contains seven moon stations. The eighteenth moon station, Subaru, rests in the middle of the white tiger of autumn. ${ }^{14}$ In this continentally derived cosmology, the term Subaru ('united', 'congregated', 'gathered') was commonly used in Japan instead of the Chinese Mao ('hair' or 'stopping place'; Bou in Japanese). ${ }^{15}$

\section{The Myth of Amaterasu and its Possible Political Significance}

The Yayoi and Kofun periods also brought strong attempts to unify the islands under single rule with a lineal descent of power. Establishing political power in many cultures means associating with meaningful symbols of the populace, and such a process was used by rulers seeking centralized power in the early development of Japan. ${ }^{16}$ The mythology found in the Kojiki (Records of Ancient Matters) and Nihongi (Chronicles of Japan), both compiled and presented to court in the eighth century, include somewhat different versions of what is considered the seminal myth of Japanese origins, the politically useful myth of the deity

D. L. Swain, Science and Culture in Traditional Japan (Tokyo: Charles E. Tuttle Co., 1989). For the introduction of Buddhism into the Japanese islands see M. I. Como, Shotoku: Ethnicity, Ritual, and Violence in the Japanese Buddhist Tradition (Oxford: Oxford University Press, 2008) and H. Ooms, Imperial Politics and Symbolics in Ancient Japan (Honolulu: University of Hawaii Press, 2009).

${ }^{14}$ For a more in-depth understanding of moon stations, see, for example, C-Y. Chen and Z. Xi, 'The Yao Dian and the Origins of Astronomy in China' in Astronomies and Cultures, ed. C.L.N Ruggles and N. J. Saunders (Niwot, Colorado: The University Press of Colorado, 1993); Sun and Kistemaker Chinese Sky; D. S. Nivison, 'The origin of the Chinese lunar lodge system', in World Archaeoastronomy, ed. A. F. Aveni (New York: Press Syndicate of the University of Cambridge, 1989), pp. 203-18.

${ }^{15}$ Nojiri, Seimet Jiten; Nojiri, Seiza Meguri.

16 D. M. Brown, 'The Yamato Kingdom', in The Cambridge History of Japan, Vol. 1, Ancient Japan, ed. D. M. Brown (Cambridge: Cambridge University Press, 1993): pp. 108-162; J. E. Kidder, 'The Earliest Societies in Japan', in The Cambridge History of Japan, Vol. 1, Ancient Japan, ed. D. M. Brown (Cambridge: Cambridge University Press, 1993), pp. 48-107; Ooms, Imperial Politics.

Culture and Cosmos 
Amaterasu (the sun goddess) who was considered the progenitor of the imperial line. ${ }^{17}$ Philippi gives an indication of the age of sources when he states that the 'Kojiki is, as its name implies, a book of antiquities; it is a record of events which, by the seventh and eighth centuries, had become ancient history. The events had been simplified and distorted in the collective memory and were heavily encrusted with legend and myth' ${ }^{18}$

The myth of Amaterasu, drawn from Kojiki and Nihongi, recounts the story of how the sun goddess quarrelled with her brother Susanowo (embodying the power of nature) and as a result, hid herself in a cave. As an enticement to get her to emerge, her jewels were placed on the branches of a sacred tree, and then after much coaxing of other deities and seeing her image in a mirror held before her, she emerged from the cave to bring light to the world. Later, she sent her grandson (the first emperor) to rule the islands, giving him the sacred sword, the aforementioned jewels, and mirror.

Along with an assessment of the political aspects of the myth, Krupp provides an analysis of its seasonal significance which portrays the story as an allegory of the sun's departure during winter and return in spring. ${ }^{19}$ Nojiri claims that early etymological associations for the term Subaru may be found in both versions of the myth, thus giving the asterism a place in the celestial allegory along with the sun. The basis of this inclusion is in the Japanese phrase Sumaru no Tama (grouping of beads) that is used to describe the jewels of the sun goddess. ${ }^{20}$ It is significant that a common term such as the Japanese fuchi is not used to describe this grouping of beads but rather the formal use of a reading for Subaru. Given the seasonal and political significance of the myth, the astronomical association of the use of Subaru in prediction of the sun's

${ }^{17}$ B. H. Chamberlain, trans., The Kojiki: Records of Ancient Matters, Tuttle Edition, (Tokyo: Charles E. Tuttle Co., 1981), pp. 61-71; D. L. Philippi, trans., The Kojiki: Records of Ancient Matters (Tokyo: University of Tokyo Press, 1968), pp. 81-86; W. G. Aston, trans., Nihongi: Chronicles of Japan from the Earliest Times to A.D. 697, Tuttle Edition, (Tokyo: Charles E. Tuttle Co., 1972), pp. 32-63.

${ }^{18}$ Philippi, Ancient Matters, p. 4.

${ }^{19}$ E.C. Krupp, Echoes of the Ancient Skies (New York: Harper and Row, 1983), pp. 96-99; E. C. Krupp, Skywatchers, Shamans, and Kings: Astronomy and Archaeology of Power (New York: John Wiley \& Sons, 1997), pp. 196-207.

${ }^{20}$ Nojiri, Seimet Jiten, pp. 105-06. See also Nojiri, Hoshi no Shinwa, and H. Kusaka, Hoshi no Shinwa Densetsu Shuu (Legends and Mythologies of the Stars) (Tokyo: Shakai Shisou Sha, 1969). 
182 The Inspiration of Subaru as a Symbol of Cultural Values and Traditions in Japan

movement, and archaeological evidence of the Jomon discussed earlier, it is reasonable to accept Nojiri's assertion that such linguistic inclusion reflects an association of the asterism with the celestial foundation of the myth. Allegorically, just as the sun (Amaterasu) was seen to depart for the winter, jewels (Subaru or Sumaru) appeared which could be seen throughout the winter months and serve as a reminder that the sun would return with spring warmth. The myth does not associate the astronomical object of the Pleiades with a god, as is the case of the sun with Amaterasu. It rather associates the asterism with a kind of sacred tool (jewels) that has been used to relate to and entice the sun. This reflects the practical use of Subaru to predict seasonal movement, a function that was incorporated in much of the star lore that developed in ensuing centuries.

The indigenous myth of Amaterasu does not directly reflect the same kind of cosmology that Chinese and Korean influences emphasizing the North Pole incorporated. Too, though often perceived to have the same number of stars (seven) as the 'north seven stars' of the Big Dipper, Subaru did not attain the same sacred sense that these stars had in Buddhist cosmology. ${ }^{21}$ The political history of power in Japan covers many centuries in which imperial fortunes were subjugated to the rule of Shoguns, and centralized authority was often difficult to achieve. There were times of much conflict and varying levels of interaction with foreign entities. Despite many changes, however, people of the islands, as in any culture, worked and played and cared for their families, seeking every means to be a part of a functioning and productive society. ${ }^{22}$ As lore from these periods reflects, Subaru was an inspiration in much of this activity.

\section{Practical and Common Lore}

While the concept of Subaru as 'united', 'congregated', or 'gathered' is fundamentally understood throughout Japan, there are numerous localized names with variant meanings and readings found throughout the country. Local names for Subaru include: Tsuto Boshi (straw wrapper stars), Tsuchi Boshi (sledge stars), Masu Boshi (dipper stars), Mi Boshi

21 See L. Dolce, ed., The Worship of Stars in Japanese Religious Practice. Special Issue of Culture and Cosmos, Vols. 10 and 11, Nos. 1 and 2, Spring/Summer and Winter/Autumn (2007).

${ }^{22}$ G. B. Sansom, Japan: A Short Cultural History (Tokyo: Charles E. Tuttle Co., 1973); J. W. Hall, Japan from Prehistory to Modern Times (Tokyo: Charles E. Tuttle Co., 1968).

Culture and Cosmos 
(willow basket stars), Akindo Boshi (the farmer's star), Iriai Boshi (the star setting at dawn), Hitsuke Boshi (the rice crop star), Nou Boshi (the agriculture star), Nou no Hitsuke Boshi (the rice crop starting star), and Houki Boshi (brush star or broom star). ${ }^{23}$ Such is indicative of much diversity in the islands and the fact that individuals have always had associations with the asterism apart from any political significance. Lore and legend is extensive and generally takes up large portions of Japanese collections such as those of Nojiri, Kusaka, Uchida, and Hara. ${ }^{24}$ While it is impossible to ascertain exact dates of origin, virtually every local area in the islands has a history of proverbs and sayings related to the asterism. Not only did such lore provide a common symbol of work and cooperation, but it also served as a tool to meet the pragmatic needs of farmers, fishermen, and other citizens.

In some areas, people saw seven stars, and in others, six. It was rare, but up to nine were seen in some localities. Regardless, the number was often mixed into lore, sometimes in a humorous way. Subaru was frequently seen as a particular object related to activity such as a shock of grain tied together or a fishing net. Regardless of specific application, memory of the lore seemed to stretch beyond its particular use. Just a few of the many examples are given below with regional affiliation and the author's notes for several in parentheses. Different readings of Subaru are also noted in italics. These examples come primarily from Nojiri as translated by Ihara. ${ }^{25}$

\section{Time and Direction}

The location of Subaru was used as a marker for time and direction. Understanding how the asterism was used in this way requires

\footnotetext{
${ }^{23}$ See collections of earlier cited Uchida, Hoshi no Hoguen and Nojiri, Seimet Jiten for more examples; many of these are included in the section on star lore. The cited references of Shinmura, Koujien and Ozaki et al., Dai Ji Gen are also invaluable sources in Japanese.

${ }^{24}$ See previously cited Nojiri, Seimet Jiten; Nojiri, Seiza Meguri; Nojiri, Hoshi no Shinwa; Kusaka, Hoshi no Shinwa; M. Uchida, Koyomi to Tenmon: Ima Mukashi (Calendars and Astronomy: Now and Then) (Tokyo: Maruzen Co. Ltd., 1990); M. Hara, Seiza no Shinwa (Mythology of the Constellations) (Tokyo: Kouseisha Co. Ltd., 1975).

${ }^{25}$ Nojiri, Seimet Jiten, pp. 105-129 and S. Ihara, 'Historical Folklore Associated with the Asterism Subaru: A Study in Japanese Cultural Symbolism' (PhD thesis, Kochi University, 1987): pp. 8-28.
} 
184 The Inspiration of Subaru as a Symbol of Cultural Values and Traditions in Japan

consideration of how time was perceived when much of the lore related to the asterism was being constructed and used (see Figure 3). ${ }^{26}$

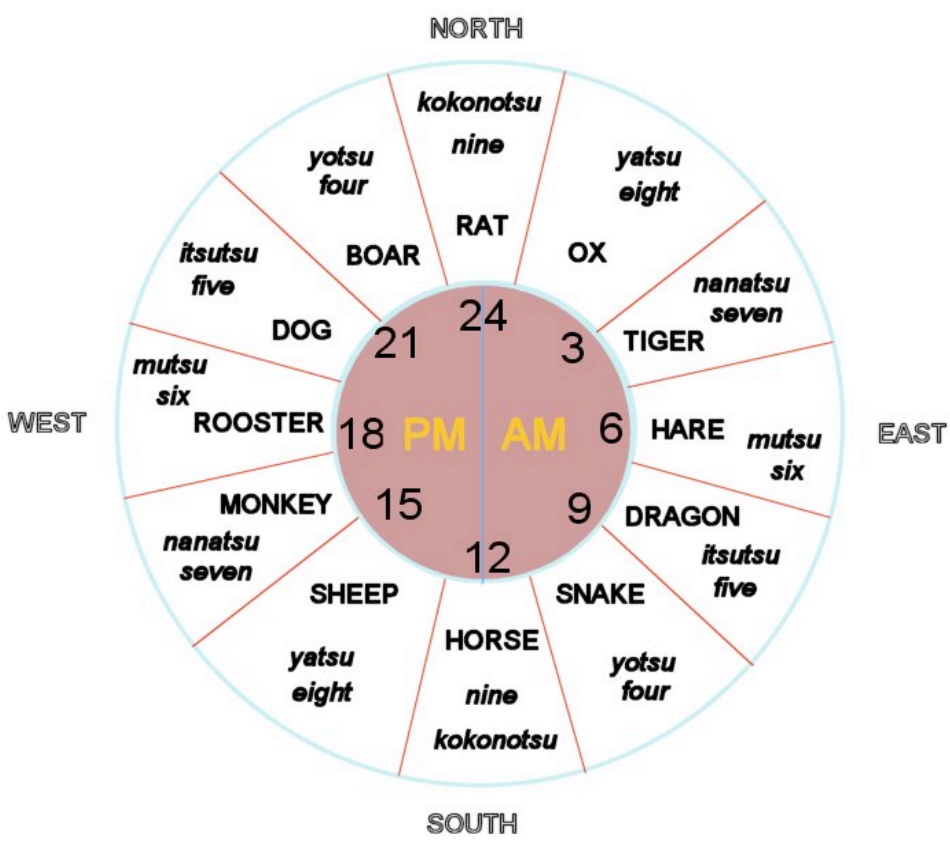

Figure 3. Time and Direction prior to the Meiji Period. ${ }^{27}$

Until the Meiji Period (1868-1912), two systems were used for time and direction. One incorporated the twelve branches of the Chinese sexagenary system (the familiar animals), and the other assigned numbers to these divisions. The correspondence of these divisions to directions north, south, east, and west as well as their correspondence to the more familiar 'western' twenty-four-hour distinction may be seen in Figure 3 The written 'number' of the numbered area as used in lore is not the same as that 'number's' hour in either a twelve or twenty-four-hour system. However, the corresponding twelve or twenty-four-hour 'time' can be

${ }^{26}$ Nojiri, Seimet Jiten, pp. 106-107.

27 A. Campbell and D.S. Noble, eds., Japan: An Illustrated Encyclopedia (Tokyo: Kodansha, 1993), pp. 154-55; Y. Okada and S. Akune, Gendai Koyomi Yomikaki Jiten (Modern Calendar Dictionary) (Tokyo: Kashiwa Shoubou, 1993).

Culture and Cosmos 
determined. For example, the time of nanatsu (seven) could refer to either 3:00-5:00 am or 3:00-5:00 pm. The direction of nanatsu could refer to ENE or WSW. In a further example, note that there are two divisions of kokonotsu (nine): one at 'Rat' (which in time would be approximately $11: 00 \mathrm{pm}$ to $1: 00 \mathrm{am}$ or from $23: 00$ to $1: 00$ in a twenty-four-hour system), and the other at 'Horse' (approximately 11:00 am to 1:00 pm or from 11:00 to 13:00 in a twenty-four-hour system).

These distinctions are further complicated by the fact that these two-hour blocks of time were not always of the same length. A day was divided into six segments from sunrise to sunset, and from sunset to sunrise. Thus, in winter, 'northern' segments areas would be longer (longer nights), and in summer, 'southern' segments areas would be longer (longer days). ${ }^{28}$ In directional usage, for latitudes of Japan, to say that Subaru is at kokonotsu (nine) would imply that it is south in 'horse' and near the zenith. Since Subaru does not appear north of the zenith, lore using kokonotsu would not imply a direction of north or 'rat'. Many sayings include both location of Subaru and time of sighting. An idea of the season of the saying can be determined by considering both. For example, the season when Subaru 'is at kokonotsu' and 'it is nanatsu' can be interpreted by considering when Subaru would be south near the zenith at about 3:00-5:00 am or 3:00-5:00 pm. At present, 3:00-5:00 am would imply late summer or early fall, maybe August or September. A time of 3:00-5:00 pm would imply late winter or early spring, maybe January or February. Obviously, the latter would be a poor interpretation of season as Subaru would be difficult to see at 5:00 or even 6:00 pm. The use of nanatsu (seven) or yatsu (eight) in lore is the aforementioned play on the perceived number of stars in Subaru. The following sayings incorporate these distinctions in time and direction: ${ }^{29}$

- Sumaru is at kokonotsu (at zenith directionally, virtually overhead); it is nanatsu at night (likely early morning around 3:005:00 am in late summer or early fall). (Southern Sanuki region)

- Ask a husband who is going somewhere secretly at night to see someone, 'what time is it?' His reply: 'Sumaru is at kokonotsu, and it is nanatsu at night' (again, probably 3:00-5:00 am in late summer or early fall). (Ehime prefecture)

\footnotetext{
${ }^{28}$ Okada and Akune, Gendai Koyomi, (in Japanese); Campbell and Noble, Japan Encyclopedia, pp. 154-55.

${ }^{29}$ Ihara, 'Folklore of Subaru', pp. 23, 24, 27.
} 
186 The Inspiration of Subaru as a Symbol of Cultural Values and Traditions in Japan

- Ask a wife who is going somewhere secretly at night to see someone, 'what time is it'? Her reply: Sumaru is at kokonotsu and eight (yatsu) heads of potatoes (1:00-2:00 am in fall around October). (Himeji city)

\section{Planting and Harvesting}

Given its position and appearance relative to spring and fall, lore can be found that relates to both spring planting and fall harvesting of a number of crops, reflecting the use of Subaru as a pragmatic tool in predicting seasonal change. Depending on area and crop, various sayings included time, a play on the number of stars perceived, and a variety of entities familiar to people in their daily life. The following examples relate to harvesting and milling: ${ }^{30}$

- When Shinmari starts to appear after the sunset (in the east in late summer), it is about time to prepare for reaping rice. (Shuubou Oo Island)

- There used to be some places to see Murika Bushi in each village. After the sun set, old farmers gathered and built a pole three hiro (about 5.5 meters) high. The time that Murika Bushi comes to make a straight line with that pole is considered as the season to sow rice (zenith sighting in early spring). (Yaezan island)

- When Subaru passes the street while you work on milling at night, it is time to go to sleep. (zenith passage late in the evening and probably around October and November). (Shizuoka prefecture)

- On the fifth month of the lunar calendar (around June), this star (sic) rises from the east around the dawn. On the tenth month of the lunar calendar (around November), it sets to the west after we finish reaping rice. This star notifies us of the rice crop. (Shizuoka prefecture)

Many of the sayings related to Subaru imply evening or night-time viewing. The last saying incorporates Subaru in heliacal rising. It is seen to start rising in the early morning in mid-summer. By November, as winter progresses, it is seen to be setting in these early hours.

${ }^{30}$ Ihara, 'Folklore of Subaru', pp. 24-25.

Culture and Cosmos 


\section{Weather}

Weather was important for a variety of activities, not limited to agriculture and fishing. The following are examples in which Subaru is considered a sign for seasonal weather conditions: ${ }^{31}$

- When Sumaru sets to the mountains in the west, the wind drops, and it is the most silent time of the day. This time is called Iriai Nagi (calm at setting [of Subaru]; early morning in late fall). (Shizuoka prefecture)

- It foretells frost when Sumaru san sets (early morning in October/November). It foretells snow when Karasuki san (reference to Orion; early morning in November/December) sets. (Tanba Shinoyama village, Kyoto prefecture)

- When the moon and Sumaru stick together or are about to be apart, weather can suddenly change (implication of a full moon together with Subaru; the sun is between autumn equinox and winter solstice, October/November). (Hakozaki city, Fukuoka prefecture)

- Tsuto Boshi on the tenth month (generally in November) is not countable because of the clearness of the sky. (Shizuoka city)

\section{Fishing}

Some proverbs speak of the relation between the position of Subaru and chances for good fishing: ${ }^{32}$

- The time that Sumari san is about to set at the edge of the mountains (probably early morning in winter, a time when squid spawn in this region) is known as Ika no Nazuki (chance for squid). It is a time that squid float to the surface of the sea. (Sado island)

- The time in which Subaru shines in the middle of the sky is called Jyuugatsu no Hoshi iri Wani (tenth month's appearance of stars), and this means the best time for sharks. Stars tell this on the tenth month (The lunar tenth month is around November; this is moving toward the winter solstice, also noted in the reference to shining in the middle of the sky or at its zenith). (Shimane prefecture)

\footnotetext{
${ }^{31}$ Ihara, 'Folklore of Subaru', pp. 22, 23, 25.

${ }^{32}$ Ihara, 'Folklore of Subaru', p. 25.
} 
188 The Inspiration of Subaru as a Symbol of Cultural Values and Traditions in Japan

\section{Balancing Relations}

The following are examples that include word play in description of relationships. Most of them locate the moon and Subaru on opposite sides of the heavens and speak of relational balance. ${ }^{33}$ The concept of 'balance' in the Japanese psyche is further discussed in the next section.

- The moon is in the east, and Subaru is in the west; my darling is in the middle. (Tango region)

- The moon is by the edge of the mountains, and Subaru is in the west; my darling is on my knee. (Hyuuga region)

- The moon is by the edge of the mountains, and Subaru Boshi is in the west; my sweet man is in the middle. (Shimane prefecture)

In these sayings, there is a sense of the 'darling' balancing moon and Subaru. If the moon is relatively full, then such sayings might be used in spring (February to April) after sunset.

\section{A Strategem}

A particularly interesting and somewhat more complex example of pragmatic lore that reflects both indigenous and externally adopted aspects of Subaru may be seen in the following stratagem written in 1654 by clansmen of Hirado (in northern Kyushu), recorded by Nojiri and translated by Ihara:

The moon should tell us of a favourable tide. However, how can we know it on a pitch-dark night? In these situations, ascertain the entrance and exit of this cluster and judge the tide. It appears at nanatsu and sets at nanatsu. Knowing this will tell you the time. Knowing the time will tell you the tide. Consider this cluster as a guide on moonless nights. This cluster is called Bou Shuku and appears as one of the twenty eight moon mansions. Subaru is a vulgar saying. The number of this cluster is seven. Judge the destiny of the next day on the night before. If the biggest star of this cluster is bright, it portends many good omens on the ground. If that star is dark, it tells of bad luck. ${ }^{34}$

\footnotetext{
${ }^{33}$ Ihara, 'Folklore of Subaru', p. 26.

${ }^{34}$ Nojiri, Seimet Jiten, pp. 106-107; Ihara, 'Folklore of Subaru', p. 8.
} 
The absence of the moon and substitution of Subaru is interesting. A 'pitch dark night' would be near the new moon and with combined forces of sun and moon, an indication of spring (high) tides (See Figure 4).
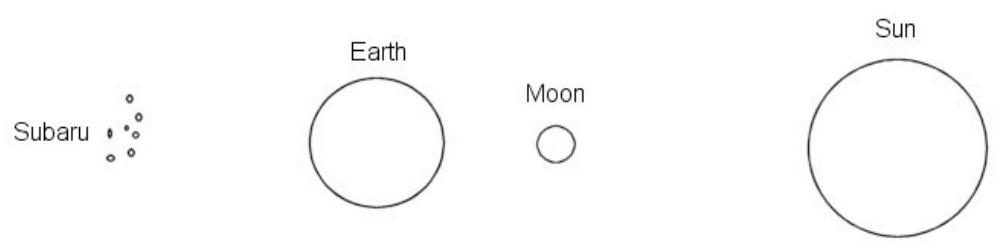

Figure 4. Positions of Sun, Moon, Earth, and Subaru in Hirado Strategem.

Associations of the perceived number of stars (seven) are interesting in the play on both possible time and direction of rising and setting (see Figure 2). A possible interpretation is that Subaru rises ENE (nanatsu direction) in early evening and sets around 4:00 or 5:00 am (nanatsu time). As recorded, the stratagem was probably used in autumn, most likely October, somewhat removed from what could have originally been closer to the equinox. As a stratagem for moonless nights, it could not be used all year round. Since the stratagem deals with fishing, and weather would be important, the darkness and brightness of the 'biggest' star would refer to atmospheric conditions. More moisture in the air would portend rain and make the star dimmer; less moisture would foretell clearer weather and a brighter star. For whatever fish were of value, this stratagem had practical use despite its lack of precision. The association of the two terms for the asterism is interesting in that it incorporates both common (in this case 'united', 'congregated', 'gathered') and more formal (moon station) significance.

The fact that the asterism had wide, familiar, and common use throughout the culture was as important as the specific use of Subaru in referencing time, season and specific activities. Unlike a celestial symbol with significant religious use, such as the aforementioned north seven stars (Big Dipper), or an imperial position such as the North Star, or 
190 The Inspiration of Subaru as a Symbol of Cultural Values and Traditions in Japan

'overwhelming' brightness as the sun, Subaru was a symbol that common citizens could easily identify with in their daily life. Thus, its supportive role in daily life made it an easy object for projection of social values.

\section{Symbolism and Psychological Identification}

For consideration of the place of Subaru as a pragmatic tool in the daily life of the Japanese, a somewhat more interpretive and sociopsychological analysis of the Amaterasu myth discussed earlier may provide another perspective on the place of Subaru in Japanese consciousness. The Jungian analyst and scholar Hayao Kawai views much of the mythology developed in early periods of Japan in terms of archetypal patterns that he argues became a part of the psyche of individual members of the society and has continued to influence perceptions to the present. ${ }^{35}$

According to Kawai, neither Amaterasu nor her brother, Susanowo (the god with whom she quarrelled) had centralized power. Centralized power resides in the symbol of the middle, an entity which maintains balance, even though opposing forces may be quite strong. The power of a central ruler (such as an emperor) or anyone in a position of authority within the culture, is not in exerting control over everything but rather in maintaining a balance and harmony in the many diverse aspects of a group or society. ${ }^{36}$ This certainly is a fundamental value of Japanese culture, even in modern times.

Where is the place of Subaru in such a view of the Amaterasu myth? Several interpretations seem possible. First, Subaru's relatively consistent and prdictable behavior relative to spring and fall place it in a position of a balancing factor in the seasonal going and coming of the sun, not in a centralized role such as could be projected on the North Pole (as in Chinese-infused cosmology), but rather in a supportive and complementary role. Second, it symbolically fills the space or emptiness of the 'lost' sun in winter (or acts as a kind of balance to the sun in the course of nature) and also in a sense the 'lost' moon on moonless nights (or a balancing with the moon as seen in lore discussed in the previous section). In this regard, it again functions in a supportive role, not in exercising power but rather in its use in timing of seasons and activities related to nature and the everyday lives of people.

\footnotetext{
${ }^{35}$ H. Kawai, Dreams, Myths, and Fairy Tales in Japan (Einsiedeln, Switzerland: Daimon Verlag, 1995), pp. 67-97.

${ }^{36}$ Kawai, Myths of Japan, p. 88.
} 
Being 'congregated' (united in a sense), and given its common associations and consistent use by people throughout society, Subaru provided a kind of archetypal symbolism for the individual giving a sense of harmonious completeness in relation to ruler and society at large. In earlier development of the country, it can be argued that the individual was expected to follow the return of the sun each spring, united in preparation for planting; following the departing sun in fall, again 'united' with others in reaping harvests. Later, as seen in much of the lore that incorporated Subaru and its association with seasonal activity, the asterism was an easy 'object' on which to project cultural values including 'vitality' in its signaling of new life in spring, 'optimism' in the prospect for a bright future, and 'lineality' in its symbolism of support for filial duty, balance of power, and social responsibility in work and civic obligation.

\section{Conclusion}

Subaru still has significance in twenty-first-century Japan, but may not be as strong in the active consciousness of today's citizens as it was for their ancestors. While they have heard some stories and studied the asterism in school, many modern Japanese may be likely to think first of the term in relation to the car company which bears the name Subaru and has six stars in its logo. Still, the fundamental values discussed above remain, and strains of nationalism and homogeneity are certainly heard at times, reflecting an aspect of the culture also seen in symbolism such as sazaraishi (individual pebbles combining and growing into rocks) mentioned in the national anthem. While perhaps lacking the full weight of its past associations, Subaru is still the term that most Japanese use to describe the asterism rather than the 'Pleiades', and it can still be seen in many references in literature, film, manga and anime, and, of course, in the name of a telescope on Mauna Kea. 